\title{
CAUSES AND INCIDENCE OF DESTRUCTIVE EYE PROCEDURES IN NORTH-EASTERN GHANA
}

\author{
M. E. GYASI ${ }^{1}$, W. M. AMOAKU ${ }^{2}$ AND M. ADJUIK ${ }^{3}$ \\ ${ }^{1}$ Emmanuel Eye Centre, P.O. Box GP8967, Accra, Ghana, ${ }^{2}$ University of Nottingham, Ophthalmology and \\ Vision Sciences, Nottingham, United Kingdom and ${ }^{3}$ Navrongo Health Research Centre, Ghana Health Ser- \\ vice, Navrongo, Ghana
}

Author for correspondence: Dr Michael Akuoba-Gyasi

Conflict of interest: None declared

\section{SUMMARY}

Objective: To determine the causes and incidence of destructive ophthalmic procedures as seen at a major reference eye centre in northern Ghana

Methods: Retrospective case series involving a review of surgical records of all evisceration and enucleation procedures done between January 2002 and December 2006 at the Bawku Hospital Eye Department. Information collected included basic demographic data, diagnosis, visual acuity at diagnosis and the eye affected. The aetiology responsible was determined from history, clinical examination and investigations as contained in the existing records. The primary clinical indications for evisceration were categorized into degenerative lesions, infections, trauma, neoplasms, and others. Statistical analysis was done using the Epi Info software.

Results: A total of 337 eyes of 336 patients made up of 217 (64.6\%) males and 119 (35.4\%) females were removed during the study period. Mean age was 36.4 with a range of 1-90 years. Children under 15 years constituted $25.1 \%$ of whom $9.3 \%$ were under 5 years. The elderly ( $\geq 60$ years) comprised $26.3 \%$. The most common cause of destructive procedure was endophthalmitis /panophthalmitis $(47.9 \%)$, ocular injuries $(23.2 \%)$, degenerative lesions $(8.9 \%)$ and neoplasms (5.1\%). Regarding neoplasms, females were more likely to be enucleated while the reverse was so for traumas $\left(\mathrm{p}=0.04\right.$ and $\mathrm{p}=0.02, \mathrm{Chi}^{2}$ test, respectively). Compared to the total number of surgeries done each year the crude incidence was computed at $26.6 \%$ per 1000 cases per year.

Conclusion: Most causes of destructive procedures in this part of Ghana are preventable and serious preventive strategies are needed to reverse this trend.

Keywords: endophthalmitis, enucleation, evisceration, neoplasms, trauma
E-mail:mikegyasi@yahoo.co.uk

\section{INTRODUCTION}

Destructive ocular procedures are usually the ophthalmologist's nightmare, and only recommended as a last resort.

This is because of the potential psychological effects of the loss of an eye to the patient and the fact that he as a clinician could not accomplish what he has been trained to do - preservation of vision and improvement of eye health. There are situations however, where such procedures are the only solution to a rather intractable problem. Current evidence shows that destructive ocular procedures are on the decline due to improved diagnosis and treatment with resultant increased globe preservation., ${ }^{\mathbf{1 , 2}}$

Among the most commonly performed procedures of evisceration and enucleation, indications appear to be the same worldwide. ${ }^{2,3}$ The relative importance of each aetiology, however, seems to differ from place to place and this appears to be related to the level of development and socio-cultural dynamics of each specific setting. In many developed countries the most important causes are orbito-ocular tumors whereas in the developing world these are often of traumatic and infectious origin. ${ }^{4,5}$

The Bawku Hospital in Northern Ghana is a reference centre for many eye diseases, including destructive surgical procedures. This study aims at determining the causes and incidence of these procedures in order to help formulate appropriate intervention strategies to help reduce same.

\section{MATERIALS AND METHODS}

This was a retrospective non-comparative case series involving the review of outpatient and surgical records of all patients who underwent evisceration or enucleation between January 2002 and December 2006 at the Hospital's Eye Department. Information collected included basic demographic data, diagnosis on admission, visual acuity at diagnosis and the eye affected. 
The aetiology responsible for evisceration was determined on the basis of history, clinical examination and investigations as determined from the existing records.

The primary clinical indications for evisceration were categorized into five groups namely: degenerative lesions, infections, acute trauma, neoplasms, and others. These primary categories were sub-divided into diagnostic groupings including anterior staphyloma, perforated corneal ulcer and ruptured globe.

\section{Statistical Analysis}

All the collected information was entered into a Microsoft Excel template and the statistical analysis done using the Epi Info 2002 (Revision 2, January 30 2003) Software. Descriptive statistics were used to summarise the characteristics of the studied subjects. Categorical variables were reported as proportions and compared among groups using the Chi-square test for significance. All statistical tests were two-sided with an alpha level of $<0.05$ considered statistically significant. Ages of the patients were summarized using the mean, standard deviation and the median. Age was further categorized into those groups of below 15 years (children), and those $15-60$ years, and those above 60 years old who were classified as elderly.

\section{Case Definition}

In this study, destructive ophthalmic procedure was defined as a surgical procedure involving the removal of part of the globe or the entire to save the fellow eye, the life of the patient or for cosmetic reasons. Specimen-taking procedures for histopathologic evaluations and restorative/reparative procedures were excluded.

\section{RESULTS}

In all, a total of 336 eyes of 336 patients were either eviscerated or enucleated over the study period. These include 64 cases in 2002, 85 in 2003, 74 in 2004, 63 in 2005 and 50 in 2006. Compared to the total number of surgical procedures done in the respective years [2238 (2002), 2,488 (2003), 3026 (2004), 2,575 (2005) and 2118 (2006)]. The average crude incidence was calculated at 26.6 per 1000 surgical procedures per year with a range of 23.6 to 34.2 per 1000 . These rates are shown in Figure 1.

Most $(70.2 \%)$ of the cases were from the northern half of Ghana with majority coming from the Upper East region $(36.0 \%)$ and the northern region $(32.4 \%)$. The rest were from Burkina Faso (16.7\%), Togo (3.6\%) and the Upper West region (1.8\%) while a handful $(0.9 \%)$ came from the Brong Ahafo and the Volta regions.

All the excisions were monocular and were of eyes which were considered blind with corrected visual acu- ity of less than $3 / 60$. The right and left eyes were affected in equal proportions of 171 versus 165 respectively.

Figure 1 Number of Eviscerations/Enucleations per 1000 surgical procedures

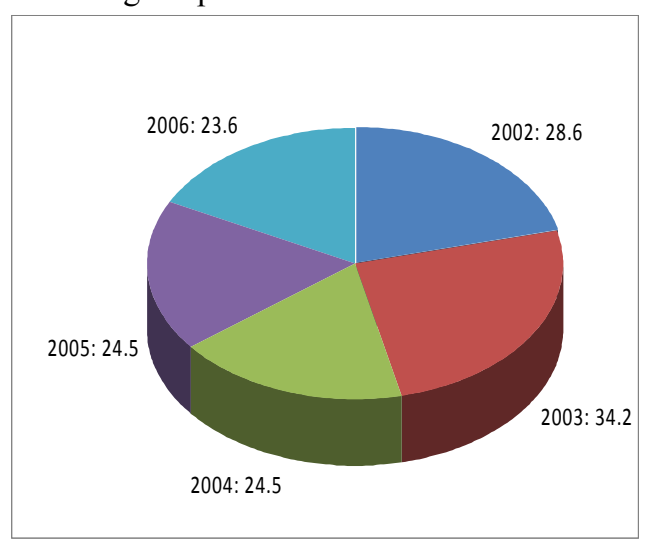

\section{Age and Sex Distribution}

Two hundred and seventeen patients $(64.6 \%)$ were males while 119 were $(35.4 \%)$ females. The median age of the patients was 35 years with a mean of 36.4 years $(\mathrm{SD}=23.3)$ and a range of 1-90 years. Children (aged less than 15 years) constituted 25.1\% among whom $9.3 \%$ were under the age of 5 years. Elderly patients (60 years and above) on the other hand constituted $26.3 \%$ of the cases. Figure 2 shows the age distribution pattern.

Figure 2 Frequency of eviscerated/enucleated eyes in each age group

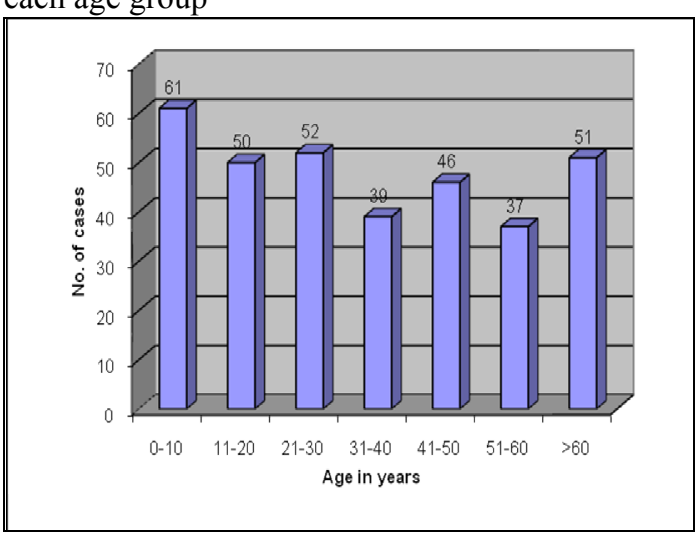

\section{Causes of Evisceration/Enucleation}

Infective lesions were the single largest cause of globe excisions carried out in the hospital $(47.9 \%)$, followed by cases related to ocular injuries $(23.2 \%)$, degenerative lesions of the eye-wall $(14.9 \%)$ and then neoplasms $(5.1 \%)$. The rest were of varied and indeterminate causes $(8.9 \%)$. 
Among the infective causes, panophthalmitis, characterized by gross infection of the uvea and sclera was the commonest and these included both post-surgical (8) and non-surgical (145) cases. With an average of 2,200 open-globe surgical procedures undertaken at the hospital each year, the post-surgical endophthalmitis rate is approximately 0.7 per 1000 cases.

Trauma accounted for $24.1 \%(n=81)$ of all the cases. These were characterized by extensive injuries to the globe and its adnexae that were considered too extensive and potentially dangerous to be preserved, due to high risks of sympathetic ophthalmia, severe phthisis and painful blind eye sequelae. They included both ruptured globes (injuries due to blunt trauma) and cases of laceration or perforation origin.

Neoplastic lesions including retinoblastomas were the least common diseases to lead to destructive procedures. However, other neoplasias (including orbital masses) were the less specific indications as histological confirmation was not always available. No reason was given for undertaking enucleations for orbital masses. Degenerative cases on the other hands were operated largely for cosmetic reasons and these included corneo-scleral ectatic lesions like anterior and intercalary staphylomas. Table1 summarizes the aetiologic factors and their distribution patterns.

Table 1 Aetiologic classification of cases

\begin{tabular}{|l|l|l|}
\hline CLASSIFICATION & $\begin{array}{l}\text { Num- } \\
\text { ber }\end{array}$ & $\begin{array}{l}\text { per- } \\
\text { cent }\end{array}$ \\
\hline Degeneration & $\mathbf{5 0}$ & $\mathbf{1 4 . 9}$ \\
\cline { 2 - 3 } $\begin{array}{l}\text { Anterior Staphyloma } \\
\text { Perforated Marginal Ulcer }\end{array}$ & 49 & 14.6 \\
\cline { 2 - 3 } $\begin{array}{l}\text { Infection } \\
\text { Perforated Cornea Ulcers } \\
\text { Pan-ophthalmitis (post-surgical) }\end{array}$ & $\mathbf{1 6 1}$ & $\mathbf{4 7 . 9}$ \\
\cline { 2 - 3 } \begin{tabular}{l} 
Pan-ophthalmitis (Nonsurgical) \\
\cline { 2 - 3 }
\end{tabular} & 7 & 2.1 \\
\hline Trauma & $\mathbf{7 8}$ & 2.4 \\
\cline { 2 - 3 } $\begin{array}{l}\text { Ruptured Globe } \\
\text { Corneosclera Lace- } \\
\text { tions/Perforations }\end{array}$ & 39 & $\mathbf{2 3 . 2}$ \\
\hline Neoplasms & 39 & 11.6 \\
\hline $\begin{array}{l}\text { Retinoblastomas } \\
\text { Proptosis of unknown origin }\end{array}$ & $\mathbf{1 7}$ & 11.6 \\
\cline { 2 - 3 } Other neoplastic lesions & 2 & $\mathbf{5 . 1}$ \\
\hline Others $\begin{array}{l}\text { Phthisis Bulbi } \\
\text { Painful Blind Eyes }\end{array}$ & 3 & 0.6 \\
\hline TOTAL & $\mathbf{3 0}$ & $\mathbf{8 . 9}$ \\
\cline { 2 - 3 } & 5 & 1.5 \\
\cline { 2 - 3 } & 23 & 6.8 \\
\hline
\end{tabular}

\section{Sex Distribution}

Table2 shows the distribution among the two sexes. There was no statistically significant difference in pattern distribution among males and females with regards to infection-related destructive procedures. However, females were nearly three times more likely to be enucleated as a result of neoplastic lesions as compared to males while in the trauma-related cases males were nearly twice as likely to be affected as females; these difference were statistically significant $(p=0.04$ and $\mathrm{p}=0.02, \mathrm{Chi}^{2}$ test, respectively).

\section{Pattern in Children}

One out of every four eyes surgically destroyed was of a child $(<15$ years $)(n=84)$, of who $27.4 \%(N=23)$ were below the age of five years. Trauma constituted the commonest cause of evisceration or enucleation among these subjects; this was followed by infection, degenerative lesions and neoplasms. Among the under-fives however, neoplasms were by far the commonest cause accounting for some $65.2 \%(\mathrm{n}=15)$ followed by infections and trauma at respective rates of $13.0 \%$ each. All the neoplastic lesions in this age group were retinoblastomas. Histopathologic evaluations confirmed $88 \%$ of these to be of poorly differentiated exophytic type. Local infiltrations and Grade 4 optic nerve invasion were observed in $50 \%$ of these specimens.

Table 2: Distribution of cases by sex

\begin{tabular}{|l|l|l|l|l|l|}
\hline Disease & Males & $\begin{array}{l}\text { Fe- } \\
\text { males }\end{array}$ & $\begin{array}{l}\text { Odds } \\
\text { Ratio }\end{array}$ & $\mathbf{9 5 \%}$ CI & $\begin{array}{l}\text { P- } \\
\text { valu } \\
\text { e }\end{array}$ \\
\hline Degeneration & 30 & 20 & 0.79 & $0.41-1.54$ & 0.46 \\
\hline Infection & 104 & 57 & 1.00 & $0.62-1.61$ & 0.99 \\
\hline Neoplasms & 7 & 10 & 2.75 & $0.93-8.27$ & 0.04 \\
\hline Trauma & 59 & 19 & 1.97 & $1.07-3.64$ & 0.02 \\
\hline Others & 17 & 13 & 0.69 & $0.31-1.58$ & 0.34 \\
\hline
\end{tabular}

\section{Pattern in the Elderly}

Seventy nine eyes of elderly patients were removed over the study period. Infection was the commonest cause accounting for three out of every four eyes $(72.2 \%)$ of these procedures in this age-group. The rest were trauma $(13.9 \%)$ degenerative lesions $(6.3 \%)$, neoplasms $(1.3 \%)$ and others $(6.3 \%)$.

\section{DISCUSSION}

In this largely rural community in northeastern part of Ghana, the commonest causes of destructive procedures was either due to panophthalmitis $(47.9 \%)$ or severe ocular injuries in which globe preservation procedures were either not possible or considered unsafe $(23.2 \%)$. These leading roles of infection and trauma are however not unique to this study as similar trends have been reported in a number of developing countries. 6,7 
In a northern Indian study, $78.6 \%$ of all eviscerated eyes were reported to be due to panophthalmitis while another $21.3 \%$ were due to irreparable globe injury. ${ }^{8}$ The high incidence of infective causes in this study probably reflects the poor socioeconomic environment in which these communities thrive. In the 2000 population and housing census in Ghana, $68 \%$ and $70 \%$ of the populations in the UER and NR were recorded to be dependent on subsistence (peasant) agriculture as the primary source of livelihood. The same survey also reported that both the UER and the NR have the highest levels of illiteracy in the country $(78.1 \%$ and $78.7 \%$ respectively). ${ }^{9}$

With this level of education and way of life as peasant farmers, their vulnerability to the use of harmful traditional herbal preparations in treating ocular ailments cannot be over-emphasized. Our study did not specifically look into the use of such harmful traditional practices. However, in a Nigerian study which also found a high incidence of infection-related destructive procedures, the authors reported that $37.5 \%$ of the patients had used traditional eye medications (TEM) while another $53.5 \%$ had used eye drops (purchased over the counter), possibly containing steroids, prior to their presentation to the hospital. ${ }^{\mathbf{1 0}}$

In a rural Indian study investigating the role of TEM in the management of corneal ulcers, the authors reported that $47.7 \%$ of the studied patients had applied TEM prior to presenting at the eye centre. ${ }^{11}$ These practices are not likely to be too different from what pertains in this part of Ghana and indeed in other parts of the country where people in rural communities use all kinds of traditional eye medications prepared under unhygienic conditions.

In the cities and larger towns individuals are more likely to start with self medication with over the counter eye drops, many of which are likely to contain steroids, as reported in this Nigerian study. The importance of this is not only limited to the complications associated with corneal ulcerations and infections but also to the more serious complications like glaucoma and delayed wound healing. The high incidence of these infection-related destructive procedures among elderly patients in the study is quite disturbing but not entirely unexpected. In most rural communities, the older persons are also the main custodians of harmful practices and cultures, and serve as the first point of call in administering traditional treatments for various ailments. In this series, the high proportion $(23.5 \%)$ of individuals above the age of 60 years undergoing globe excisions is very significant when contrasted with the fact that this age group constitutes only 9.0\% (UER) and $6.5 \%(\mathrm{NR})$ of the population. ${ }^{9}$
Of related importance are excisions due to corneoscleral degeneration, particularly anterior staphyloma, a condition which is largely associated with complications of infective corneal ulcers. In a 2002 multicentre collaborative study in corneal ulcers, the authors reported filamentous fungi and pseudomonas species as the most common aetiologic organisms for corneal ulcers in the UER. When properly treated with the appropriate antimicrobial agents many of these ulcers healed with acceptable visual outcomes and these underline the importance of receiving appropriate treatment instead of using self-medication and application of TEMs. ${ }^{21}$

The excision of eight cases due to post-surgical infections is unfortunate. However, the post-surgical endophthalmitis rate of some 0.7 per 1000 cases is within acceptable limits, for a rural setting. While such incidence can be minimized it is impossible to eliminate them completely especially in high-volume cataract surgery centres in a rural setting like Bawku. Notwithstanding these, however, more needs to be done to reduce the incidence of such cases.

These globe excisions included a significantly large numbers of children. The high person blind years and psychosocial implications associated with paediatric sight loss cannot be overstated in these circumstances. The high incidence among such a vulnerable group is a reflection of the lack of a comprehensive capacity to manage such cases adequately in a country setting where there are only one or two paediatric ophthalmologists caring for some 11 million children (census report). ${ }^{9}$ Furthermore, the high incidence of trauma and infection among the cases reflects the inadequacies in our preventive eye care services and the weaknesses within the national public health care structures.

Among children less than 5 years retinoblastomas were the commonest causes, consistent with reports in the literature. ${ }^{12,13,14}$ The higher incidence of neoplastic lesion among female subjects in this study will need further evaluation in a larger study. The high incidence of poorly differentiated forms on histologic evaluation is also consistent with other findings among African children. ${ }^{15}$ It is possible that enucleations performed for 'orbital masses' were palliation for extended intraocular tumours, or significant globe displacement from orbital masses. The late presentation among these patients and findings of extensive local infiltration on histologic evaluation mean that a lot of work needs to be done in educating people to identify early presentations of such conditions and report for clinical assessment and management. 
There are significant variations in the indications/aetiology and frequencies of globe excisions. In most studies reported from teaching hospital settings in large towns and cities the commonest causes are likely to be trauma, and contrast sharply with reports originating from rural settings. ${ }^{2,16,17}$ In cosmopolitan settings people are more likely to be educated with less likelihood of having an agrarian way of life, and to use traditional herbal medications, two factors that appear to positively contribute to the incidence of infective destructive procedures.

The rural dwellers are also more likely to have reduced access to modern hospital eye care services. The role of ocular injuries as a major cause of enucleation/evisceration has been reported in several other studies. ${ }^{18,19,20}$ Education of the population on hazards of ocular injuries and their poor outcomes, as well as avoidance of herbal medication and improved access to eye care will significantly reduce globe excision from such causes.

\section{CONCLUSION}

Unlike many developed countries where the causes of destructive procedures are likely to be of nonpreventable neoplastic origin, most of the causes of globe excision in this study are largely preventable. There is the need to improve on eye health education and better access to eye care at all levels.

\section{REFERENCES}

1. Saeed MU, Chang BY, Khandwala M, Shivane AG, Chakrabarty A. Twenty year review of histopathological findings in enucleated/eviscerated eyes J Clin Pathol 2006;59(2):153-5.

2. Tahri H, Benatya AD, Chefchaouni CM, El Bakkali M, Berraho A. Enucleations: epidemiologic investigation in Morocco. presentation of 183 cases Bull Soc Belge Ophtalmol 2004;(292):31-4.

3. Epee E, Masanganise R. The rate of and indications for enucleations at Sekuru Kaguvi Eye Unit in Harare: a comparative analysis. Cent Afr J Med 2003;49(1-2):13-5.

4. Kaimbo K. Causes of enucleation in Zaire $\mathrm{J} \mathrm{Fr}$ Ophtalmol 1988;11(10):677-80.

5. Shapiro A, Monselise MB. Destructive ophthalmic procedures, a comparison between a developed and a developing country. Albrecht Von Graefes Arch Klin Exp Ophthalmol. 1978; 207(4):271-3.

6. Bekibele CO, Oluwasola AO. A clinicopathological study of orbito-ocular diseases in Ibadan between 1991-1999 Afr J Med Med Sci. 2003 Jun;32(2):197-202.
7. Haile M, Alemayehu W. Causes of removal of the eye in Ethiopia. East Afr Med $J$ 1995;72(11):7358 .

8. Dada T, Ray M, Tandon R, Vajpayee RB. A study of the indications and changing trends of evisceration in North India Clin Experiment Ophthalmol 2002;30(2):120-3.

9. Ghana Statistical Service "2000 Population and Housing Census: Summary Report of Final Results". March, 2002

10. Nwosu SN. Destructive ophthalmic surgical procedures in Onitsha, Nigeria. Niger Postgrad Med $J$ 2005; 12:53-6.

11. Prajna NV, Pillai MR, Manimegalai TK, Srinivasan M. Use of Traditional Eye Medicines by corneal ulcer patients presenting to a hospital in South India. Indian J Ophthalmol. 1999; 47(1):158.

12. Belmekki $\mathrm{M}$, el Bakkali $\mathrm{M}$, Abdellah $\mathrm{H}$, Benchrifa F, Berraho A. Epidemiology of orbital processes in children. 54 cases. J Fr Ophtalmol 1999;22(3):394-8.

13. Epee E, Masanganise R. The rate of and indications for enucleations at Sekuru Kaguvi Eye Unit in Harare: a comparative analysis. Cent Afr J Med. 2003;49(1-2):13-5.

14. Ntim-Amponsah CT Ocular tumours and problems in management: a Ghanaian experience. East Afr Med J 1996;73(3):182-6.

15. Mukhtar AU, Kagame K. Pathological study of retinoblastoma in Mbarara, Uganda. Cent Afr $J$ Med 2000;46(1):13-6.

16. Mpyet C, Wade P, Ramyil A. Indications for surgical removal of the eye in adults; a five year review. Nigerian J Med 2008; 17 (1):1115-2613.

17. Haile M, Alemayehu W. Causes of removal of the eye in Ethiopia. East Afr Med J 1995; 72(11):7358.

18. Gyasi ME, Amoaku WMK, Adjuik MA. Epidemiology of hospitalized ocular injuries in the Upper East region of Ghana Ghana Med $J$ 2007; 41(4):171-5.

19. Abebe Bejiga. Causes and visual outcomes of perforating ocular injuries among Ethiopian patients. J Comm Eye Health 2001;14: 45-46.

20. 20.Vasu U, Vasnaik A, Battu RR, Kurian M, George S. Occupational open globe injuries Indian J Ophthalmol 2001; 49:43-7.

21. Leck AK, Thomas PA, Hagan M, Kaliamurthy J, Ackuaku E, John M, Newman MJ, Codjoe FS, Opintan JA, Kalavathy CM, Essuman V, Jesudasan CA, Johnson GJ. Aetiology of suppurative corneal ulcers in Ghana and South India, and epidemiology of fungal keratitis. $\mathrm{Br} J$ Ophthalmol 2002 Nov;86(11):1211-5. 